\title{
ANÁLISE DOS WEBSITES \\ OFICIAIS DOS DESTINOS TURÍSTICOS CLASSIFICADOS SOCIOCULTURALMENTE PELA REVISTA THE ECONOMIST INTELIGENCE UNIT LIMITED
}

\section{ANALYSIS OF THE OFFICIAL WEBSITES OF TOURISM DESTINATIONS CLASSIFIED SOCIOCULTURALLY BY THE REPORT THE ECONOMIST INTELIGENCE UNIT LIMITED}

\section{ANÁLISIS DE LOS SITIOS WEB OFICIALES DE LOS DESTINOS TURÍSTICOS CLASIFICADOS SOCIOCULTURALMENTE POR LA REVISTA THE ECONOMIST INTELIGENCE UNIT LIMITED}

Juliana Rodrigues Ferreira Universidade Federal do Rio Grande do Norte Graduada em Turismo pela Universidade Federal do Rio Grande do Norte Natal, Rio Grande do Norte, Brasil julianafe88@gmail.com

\section{Lissa Valéria Fernandes Ferreira}

Universidade Federal do Rio Grande do Norte Docente da Universidade Federal do Rio Grande do Norte Doutora em Administração de Empresas pela Universitat de Barcelona, UB, Espanha. Natal, Rio Grande do Norte, Brasil lissaferreira.iadb@yahoo.es

\section{Aureo Paiva Neto} Universidade Federal do Rio Grande do Norte 
Natal, Rio Grande do Norte, Brasil aupan2002@hotmail.com

Data de submissão: 23/02/2016

Data de aprovação: 07/06/2016

RESUMO: Devido ao aumento da acessibilidade do turismo pela população mundial, os destinos turísticos têm investido na internet, por meio de websites, como forma de divulgação das cidades, oferecendo aos usuários informações sobre o destino a ser visitado. Nesse contexto, o presente trabalho analisou qualitativamente os websites oficiais das cidades que ficaram entre as três primeiras colocadas no ranking de competitividade sociocultural, promovido pela revista The Economist Inteligence Unit Limited, em 2012, procurando verificar sua eficiência quanto à distribuição de informações turísticas ao consumidor. Foram utilizadas técnicas, como a análise "DAFO" e os Fatores Críticos de Sucesso em Websites, propostas pela Organização Mundial do Turismo. Como resultado, percebeu-se que os websites oficiais de turismo, mesmo pertencendo a grandes destinos internacionais, apresentam ainda deficiências que devem ser corrigidas para melhorar a qualidade de comunicação entre destinos e turistas.

PALAVRAS-CHAVE: Turismo; Marketing Digital; Tecnologia da informação.

ABSTRACT: Due to the increased accessibility of tourism by the world's population, tourist destinations have invested in the internet, through websites, as a mean of advertising the attractions of cities and providing information for potential visitors about the destination. In this context, this paper carried out a qualitative analysis of the official websites of some cities that were among the top three in the ranking of sociocultural competitiveness promoted by The Economist Intelligence Unit Limited in 2012, seeking to determine their efficiency in regard to the distribution of tourist information to consumers. The techniques of SWOT analysis and the Critical Success Factors for Websites, proposed by the World Tourism Organization, were used. As a result, it was found that the official tourism websites, even though they created by major international destinations, still have weaknesses that must be corrected, in order to improve the quality of communication between destinations and tourists.

KEYWORDS: Tourism; Digital Marketing; Information Technology.

RESUMEN: Debido al aumento de la accesibilidad del turismo por la población mundial, los destinos turísticos han invertido en la internet por medio de sitios web como forma de divulgación de las ciudades, ofreciendo a los usuarios informaciones sobre el destino a ser visitado. En ese contexto, el presente trabajo analizó cualitativamente los sitios web oficiales de las ciudades que están entre las tres primeras colocadas en el ranking de competitividad sociocultural, promovido por la revista The Economist Inteligence Unit Limited en 2012, procurando verificar su eficiencia en relación a la distribución de informaciones turísticas al consumidor. Se utilizaron técnicas como el análisis "DAFO" y los Factores Críticos de Éxito en Sitios Web, propuestas por la Organización Mundial del Turismo. Como resultado se observó que los sitios web oficiales de turismo, aun perteneciendo a grandes destinos internacionales, todavía presentan deficiencias que deben ser corregidas para mejorar la calidad de la comunicación entre destinos y turistas. 
PALABRAS CLAVE: Turismo; Marketing digital; Tecnología de la información.

\section{INTRODUÇÃO}

presença da internet na vida das pessoas tem aumentado
consideravelmente nos últimos anos. De acordo com a ITU
(International Telecommunication Union), o volume de indivíduos que utilizam a internet continua a crescer em todo o mundo, e até o final de 2015 já atingiu o patamar de 3,2 bilhões de pessoas on-line, dentre os quais aproximadamente 2 bilhões se situam em países desenvolvidos.

No Brasil, segundo o IBGE (2011), o número de brasileiros com dez anos ou mais de idade que acessaram ao menos uma vez a internet foi de 77,7 milhões, enquanto que em 2009 esse número foi estimado em 67,7 milhões. Analisando este cenário entre os anos de 2005 a 2011, o contingente de pessoas que acessaram a internet cresceu 45,8 milhões.

Sendo assim, o rápido crescimento do número de usuários on-line, aliado ao aumento da taxa de transações on-line comprovam a popularidade da tecnologia. Empresas de vários setores, incluindo o turismo, que são orientadas para o relacionamento com clientes e para a dinamicidade de troca de informação intensiva, têm adotado cada vez mais modelos de e-business (comércio eletrônico) para atingir seus objetivos organizacionais. Portanto, manter um portal eficaz na internet tornou-se uma ferramenta essencial para um negócio que deseja reforçar as suas relações com os clientes e ampliar a sua segmentação no mercado (Law, Qi e Buhalis, 2010).

Uma vez que a internet se tornou uma ferramenta essencial no planejamento e na organização de diversas atividades humanas, percebese também que tal prática se aplica ao setor de turismo. Atualmente, é possível planejar on-line todas as etapas de uma viagem, como comprar bilhetes aéreos, reservar serviços de hospedagem, adquirir ingressos de atrações, visualizar mapas, alugar automóveis e buscar dicas e avaliações de passeios e restaurantes. 
Fica evidente, portanto, a evolução de serviços on-line do turismo. Companhias aéreas têm facilitado a compra de passagens pela internet; grande parcela dos hotéis, pousadas e hostels ao redor do mundo disponibilizam suas reservas online; atrações turísticas criaram websites para oferecer acesso às informações desejadas e, até mesmo, possam ser vendidos ingressos antes mesmo de chegarem ao destino. Muitos são os artifícios usados pelas empresas de turismo e pelos próprios destinos turísticos e isto certamente facilita a propagação de seus serviços, atraindo mais visitantes, hóspedes e compradores.

Um indício dessa grande mudança é o crescimento do número de turistas que passou a planejar suas próprias viagens on-line, ao invés de contratar serviços de agências. Em sua última pesquisa publicada sobre os hábitos de consumo do turismo do brasileiro, o Ministério do Turismo averiguou que, em 2009, 39,1\% dos clientes já utilizavam a internet como fonte de informação sobre viagens, em oposição a apenas 5,6\% que utilizavam o serviço de agências de viagens.

A OMT (Organização Mundial de Turismo), em sua publicação E-Business para Turismo (2003), afirmou que o setor do turismo e a internet são parceiros ideais, já que os consumidores, ao planejarem sua primeira viagem a um destino, enfrentam o problema de realizar uma compra sem que possam ver o produto. É justamente essa uma desafiadora característica do setor de serviços: a sua intangibilidade, uma vez que, no caso do turismo, o serviço não pode ser avaliado antes do seu consumo (Buhalis, 1998; Kuo et al., 2015).

Alia-se então à internet como reforço ao setor de turismo, proporcionando o acesso imediato a informações importantes a respeito dos destinos ao redor do mundo, além de permitir fazer reservas e realizar a compra de forma rápida e fácil (Tomikawa, 2009). Uma vez que a informação é fundamental ao turismo, a tecnologia se torna indispensável para a operação qualificada do setor (Cooper et al., 2007).

Uma das principais fontes de acesso a essas informações, muito usadas por turistas, são os websites de destinos turísticos. Segundo a OMT, destino turístico se define como "o local visitado que é central para a decisão de fazer a viagem" (OMT, 2008), e são os sites destes destinos - muitas vezes desenvolvidos por secretarias, órgãos e/ou entidades turísticas da própria cidade em questão - que 
visam propagar a atividade turística na localidade. Tais websites se mostram muito úteis no planejamento de viagens por parte dos consumidores, pois disponibilizam informações variadas sobre acomodação, dicas de gastronomia, horários e preços de atrações locais, atividades, eventos, esportes, mapas, transporte, dentre diversas outras.

Entretanto, provenientes dos avanços da internet e da sua associação ao setor turístico surgem importantes desafios para o marketing de destinos. Isso se dá devido à citada intangibilidade do turismo, o que obriga dessas organizações de divulgação um maior esforço para criar associações mentais desejadas pelos viajantes, muitas vezes influenciados pela emoção neste segmento (Morrison, 2012).

Então, ao pensar nesses sites com o intuito de se planejar uma viagem, prontamente enfrentam-se as seguintes questões: qual o nível de qualidade das informações presentes nesses websites? Eles conseguem transmitir de forma eficiente o leque de informações que os turistas precisam ter antes de visitar aquela localidade?

Nesse contexto, ao saber que a internet aparece como a principal fonte de informação dos turistas em potencial, além de reconhecer a importância dos websites de destino turístico para os visitantes de uma determinada localidade e no planejamento de suas viagens, este trabalho tem por finalidade analisar a qualidade das informações prestadas por esses sites e, consequentemente, verificar a eficiência das informações neles presentes como ferramentas de marketing de destinos turísticos. Sabe-se que os websites de destinos turísticos têm se especializado, mas será que estão se aproximando desse ideal?

Percebe-se, portanto, a importância de se fazer uma análise desses websites, na busca por verificar a qualidade das informações neles presentes e entender a eficiência com que repassam as informações; bem como saber se possibilitam que o usuário adquira as informações necessárias para planejar sua viagem de forma satisfatória. Os pesquisadores acadêmicos há muito tempo defendem que a imagem de destinos já é um assunto massivamente discutido, enquanto que pouco se discute a função da Internet como o agente formador dessa imagem (Choi et al., 2007). Sendo assim, é enfatizada a importância de uma 
avaliação cada vez mais efetiva dos websites de destinos turísticos (Law, Qi e Buhalis, 2010).

Além disso, autores apontam que existe ainda a necessidade de mais investigações sobre o impacto das informações e do design do website na qualidade do serviço percebido e intenção de compra (Dedeke, 2016), especialmente considerando que a internet está envolvendo cada vez mais destinos ao redor do mundo, e que pesquisadores do comportamento do consumidor vem há muito tempo investigando como os consumidores processam informações (Rodríguez-Molina et al, 2015).

Assim, justifica-se a importância de uma análise dos websites de destinos turísticos, para que sejam observadas a qualidade e a eficiência das informações prestadas por esses sites, descobrindo a capacidade desses de informar o turista de maneira eficiente, tornando-se um guia da região para os visitantes independentes e contribuindo com que os turistas, de uma maneira geral, se informem sobre o local a ser visitado.

Portanto, o objetivo deste estudo é analisar qualitativamente os sites dos destinos turísticos classificados como os primeiros colocados no ranking de competitividade sociocultural promovido pela revista The Economist Inteligence Unit Limited, em 2012, buscando verificar a eficiência da ferramenta "portais de destinos turísticos" para o planejamento de viagens turísticas on-line.

\section{CONCEITOS TURÍSTICOS}

Segundo a OMT (2008), o turismo é "um fenômeno social, cultural e econômico que implica o movimento de pessoas para países ou lugares fora do seu ambiente habitual para fins pessoais ou profissional/comercial". O que se tem percebido é o crescimento do turismo em vários de seus segmentos. A necessidade de interação, nos âmbitos comercial, profissional e pessoal, tem aumentando na realidade das pessoas, devido à aceleração de uma rotina de trabalho em que falta tempo para socializar, fazendo-as buscar aproveitar ao máximo o tempo livre que conseguem para trocar experiências. 
Percebe-se então que, no turismo, os produtos e os serviços são consumidos de forma conjunta, construindo a experiência que é vivida pelo turista durante sua viagem. Alexandre Biz (2009) considera que o turismo está enquadrado no setor de serviços e ao contrário dos demais setores, os serviços são caracterizados pelo consumo simultâneo do consumidor (faz parte do processo) durante a produção e pelos atributos relativos que são difíceis de demonstrar, além de ser composto por elementos e percepções intangíveis, e de ser sentido pelo consumidor como uma experiência.

Entende-se, portanto, que o turista está inserido no processo produtivo do turismo e consome os serviços ao mesmo tempo em que realiza atividades turísticas. O turismo, por sua vez, é composto por diversos segmentos que proporcionam ao turista uma experiência completa que é formada por cada um dos produtos e dos serviços consumidos pelo viajante. Ainda para Biz (2009), "pode-se afirmar que o turismo dispõe de um complexo canal de distribuição pela integração de um amplo número de prestadores de serviços e de novos intermediários (agências de viagens online, organizações públicas e privadas, entre outros)".

Alguns desses novos intermediários, surgiram com o avanço da internet: as agências de viagens on-line, os portais turísticos, os sistemas de reservas de passagens e hotéis pela internet. Todos são exemplos das novas ferramentas que estão facilitando e agilizando o processo de planejamento de viagens. O turista está tendo a chance de se tornar independente e ir em busca de informações por conta própria. Biz (2009) afirma que "a configuração da experiência turística é gerenciada por alguns prestadores de serviços que constituem uma rede que disponibiliza ao usuário final a possibilidade de uma escolha orientada (oferta de produtos e serviços)".

Guimarães e Borges (2008) afirmam que muitas vezes "o turista deseja visitar um local que não conhece ou sobre o qual tem poucas informações experienciais. (...) Nessa situação o turista recorre a diversas fontes". A internet, desta maneira, se torna uma grande aliada, fornecendo variadas fontes de informação.

Sendo assim, as empresas turísticas têm se preocupado cada vez mais com a forma de agir do consumidor e com seu perfil. Tais organizações, na busca por se aperfeiçoar e proporcionar aos clientes uma experiência única, têm visto 
na internet uma ferramenta muito útil, utilizada muitas vezes para agilizar o processo de compra e para fornecer mais informações aos consumidores.

\section{INFORMAÇÕES PARA O TURISMO}

A comunicação é fundamental para qualquer relação, tanto pessoal quanto econômica. No setor do turismo, a troca de informações se mostra ainda mais necessária e vital. Corpas e García (2007) afirmam que "em nossa sociedade super comunicada, se dá o paradoxo de que nada é mais importante que a comunicação. Com ela tudo é possível; sem ela, nada se pode alcançar, por mais inteligente e ambicioso que seja".

No turismo, a qualidade da informação é de fundamental importância, pois ela proporcionará que os turistas estejam cientes do que irão encontrar, possibilitando que estes usufruam dos produtos e/ou serviços da forma que desejam acesso a informações diversas sem mesmo saírem de casa.

Logo, empresas, entidades e destinos turísticos devem focar na qualidade dos dados que fornecem para que sejam eficientes nos seus propósitos. Para Biz (2009), "a informação vem sendo identificada como um dos mais importantes parâmetros de qualidade para a eficiência do serviço e pode representar um grande poder para quem a gerenciar". Fornecer informação de qualidade significa ganhos para as empresas e, com uma boa gerência desses dados, uma vez que ela pode influenciar escolhas feitas por consumidores, inclusive na tomada de decisão de compra.

Ao compreender as necessidades do consumidor, torna-se possível traçar estratégias para atender a essas necessidades e satisfazer o cliente. Desta forma, Biz (2003) apud Biz (2009), dividiu informações no turismo em três etapas: 1) informação acerca do destino turístico: o que é, a sua importância, quais os seus atrativos; 2) informação acerca da logística: qual o melhor caminho (rota e transporte), quais os lugares para descanso (hospedagem e alimentação), quais as garantias de segurança; 3) informação utilizada para a comercialização do produto.

Tomando como base essas três etapas, será possível informar ao consumidor fatos e notícias que colaborarão para a tomada de decisão de compra, já que 
o turista se sentirá satisfeito e confortável com este leque de informações que possibilitará uma visão ampla do destino a ser visitado.

Para Guimarães e Borges (2008), "independente da motivação e da forma como é organizada a viagem, seu planejamento é fundamental e demanda informações sobre destinos, atrações, acessos, acomodações e serviços oferecidos".

A informação é fundamental ao turismo e por isso a tecnologia se torna indispensável para a operação qualificada do setor (Cooper et al., 2007). Notase hoje que muitos turistas dispensam as operadoras e as agências de viagens na hora de planejarem suas viagens. Os sites de destinos turísticos, por sua vez, prestam um serviço de informar os consumidores de como a localidade a ser visitada funciona, informando sobre atrações, hospedagem, gastronomia e transporte. No caso dos portais de destinos turísticos, a informação é o principal serviço oferecido, já que a finalidade destes sites é fornecer ao consumidor dados que possibilitem um mapeamento, mesmo que geral, do destino selecionado. Assim, percebe-se a importância de fornecer a esse consumidor informações precisas e contundentes, que o levarão a uma ideia ampla da região e suas atrações.

\section{TECNOLOGIA DA INFORMAÇÃO E COMUNICAÇÃO (T.I.C.)}

A globalização é impulsionada pela tecnologia. A tecnologia da informação permite a troca de informações entre países, empresas e pessoas ao redor do mundo, enquanto a tecnologia do transporte provoca trocas físicas (Kotler et al. 2010). Esse acesso à informação e aos canais de distribuição sofreram uma alteração considerável comainserção da tecnologia da informação ecomunicação (T.I.C.) no mercado turístico, o que possibilitou ao consumidor o acesso direto aos prestadores de serviços locais e/ou utilizando os intermediadores (operadoras turísticas, agências de viagens tradicionais e virtuais), o que provocou mudanças organizacionais e administrativas de Organizações Públicas e Privadas, dentre as quais destaca-se a criação dos Portais Turísticos por parte das Organizações Públicas de Turismo (Biz e Ceretta, 2008). 
Dentre implicações expressivas sobre o uso da internet para o turismo estão a facilidade no acesso à informação e a redução do tempo para a tomada de decisões (Brilhante e Corrêa, 2015). Desta forma, a parceria do turismo com a tecnologia da informação, neste caso representada pela internet, mostrase inevitável. As possibilidades criadas pela internet permitem que o usuário obtenha uma quantidade suficiente de informações que o permite planejar sua viagem com segurança.

O turismo foi muito beneficiado com a internet. A partir dela, consumidores podem encontrar informações, fotos, mapas e até mesmo opiniões sobre diversos destinos ao redor do mundo. $O$ turista tem acesso a uma diversidade de dados que contribuem para um planejamento mais eficiente de uma viagem turística. Para Tomikawa (2009), "o turista da atualidade deseja e procura produtos turísticos individualizados, pois ele próprio sente-se um sujeito distinto/singular na rede mundial de computadores".

Os impactos provocados pela T.I.C. afetaram no turismo a sua forma de produção, distribuição e marketing nas entidades governamentais e privadas (Buhalis, 1998). Desta forma, percebe-se a importância dos websites turísticos e verifica-se que empresas e entidades de turismo devem elaborar estratégias para usufruir dessa oportunidade. Tomikawa (2009) afirma que "a consolidação da rede como mídia tem afetado a indústria do turismo e o comportamento de seus consumidores. Hoje, portanto, é imprescindível que qualquer destino turístico esteja presente na Web. E o primeiro passo para isso é a construção de um website".

Fica clara, portanto, a importância das Tecnologias da Informação e Comunicação para o turismo. Através de ferramentas como a internet, empresas interagem com consumidores e agilizam o processo de compra do produto/ serviço. A internet conectou a oferta turística com sua demanda, possibilitando a integração de organizações e clientes, além de deixá-los mais independentes e seguros dos produtos que estão comprando. A partir de websites turísticos, o turista tem acesso às informações que deseja na hora em que deseja.

Quando se trata mais especificamente de destinos internacionais, o papel dos intermediários - agentes e operadores de turismo - na promoção e na criação de imagens dos destinos se torna ainda mais importante, uma vez que esses 
viajantes internacionais tendem a precisar de apoio em seu processo de seleção de destino (Baloglu \& Mangaloglu, 2001). Contudo, a independência que vem criada por causa da internet está cada dia mais evidente, tanto é que um estudo feito por Hyde (2006) com turistas internacionais apontou que a internet foi a principal fonte de pesquisa sobre acomodações na Nova Zelândia.

\section{A INTERNET COMO FERRAMENTA DO TURISMO}

Para Guimarães e Borges (2008), "a expansão da internet ocorreu (...) abrindo oportunidades sem precedentes para distribuição de informação e para interatividade entre consumidores e fornecedores em praticamente todas as atividades econômicas".

O surgimento da internet e do computador no período pós-moderno provocou uma grande revolução na vida do homem, bem como no turismo, que passou por grandes e impactantes transformações (Lohmann e Panosso Netto, 2012), uma vez que a sociedade e as organizações passaram a acessar informações independentemente da sua localização e muitas vezes sem qualquer tipo de custo (Cooper et al., 2007).

A tecnologia da informação possibilitou ao turismo um desenvolvimento jamais visto, já que a internet permite que turistas comprem serviços e produtos de forma fácil, rápida e segura mesmo antes do consumidor começar sua viagem. Isso faz com que o cliente se sinta mais confiante em viajar, além de que facilita a tomada de decisão da compra, já que ele não precisará buscar intermediários, como agências de viagens, para consolidar seus desejos de viajar, tornando-se, assim, mais independente.

Entretanto, essa independência do consumidor só se torna possível quando as informações disponibilizadas para eles nos sites turísticos são confiáveis, ou seja, o usuário desses sites precisa se sentir seguro o suficiente para efetuar a compra. Percebe-se, então, a importância da distribuição de informações de qualidade.

Tomikawa (2009) afirma que o número de usuários da web continua crescendo, o que leva a crer que se tem que trabalhar para potencializar seus aspectos positivos. É fundamental que as empresas e os órgãos turísticos façam bom 
uso de seus portais on-line, disponibilizando informações contundentes e de qualidade para que os usuários não sejam prejudicados.

Informação de qualidade é essencial para que turistas ao redor do mundo tenham a chance de realizar suas viagens como planejaram e sonharam, principalmente quando o destino escolhido é um lugar que o turista nunca visitou antes. É necessário que exista uma grande variedade de informações para que sua viagem seja tranquila. Essa necessidade se potencializa ainda mais nos casos em que a visita é feita a uma localidade que difere do país de origem do visitante.

Nesse conglomerado de redes, no qual se conectam bilhões de pessoas em uma escala mundial, há um descontrole de informações que pode muitas vezes supervalorizar ou desvalorizar um produto turístico que está em oferta (Ruschmann e Tomelin, 2013). Portanto, a utilização da internet para divulgação do turismo requer alguns cuidados, dentre eles a seleção adequada de imagens que pretende utilizar para a sua autopromoção. Por exemplo: alguns hotéis têm adotado como estratégia uma exagerada produção fotográfica de suas instalações e postando-as em seus websites. Apesar de parecer inteligente, tal tipo de prática vem provocando certas repercussões em sites que possibilitam avaliações e comentários, como o tripadvisor, em que os hóspedes criticaram e realizaram comparações entre fotos manipuladas em softwares e a imagem real e inferior encontrada ao se instalar na hospedagem, consistindo em uma situação de propaganda virtual enganosa (Kuo et al., 2015). Cuidados como esses servem também para destinos, pois os consumidores estão bastante exigentes, uma vez que atualmente já podem acessar facilmente informações e trocar opiniões entre eles sobre produtos e serviços, conforme afirmação de Park \& Lee (2008, apud Mendes Filho, 2014).

Os destinos, por sua vez, visualizaram uma oportunidade ao elaborar portais turísticos on-line que fornecessem informações variadas aos seus usuários, contendo até mesmo opção de reservas e compras. De acordo com Biz (2009), percebeu-se uma movimentação de algumas Organizações Públicas de Turismo no desenvolvimento de portais turísticos para os seus respectivos destinos turísticos, com o intuito de, além de prestar informação ao consumidor, 
possibilitar aproximação entre os consumidores e prestadores de serviços locais e não locais, favorecendo ao consumidor a tomada de decisão de compra.

De acordo com Guimarães e Borges (2008), "um portal organizado e atualizado passa a ser também um diferencial no mercado, tornando-se símbolo do destino". Para Biz (2009), os portais turísticos devem ser vistos não apenas como um canal de prestação de informações para os consumidores (finais e intermediários), mas devem ser vistos como ferramenta que possibilite a gestão do destino turístico.

É necessário que as entidades de turismo tracem planos e estratégias para desenvolverem esses portais turísticos de uma forma que atenda às necessidades e às intenções de seus usuários. Chen (2006, apud Biz e Ceretta, 2008) afirma em sua pesquisa que quatro são os fatores que inibem os consumidores para comprar mais produtos e/ou serviços on-line em virtude de dúvidas e preocupações. São elas: a) a legitimidade e autenticidade do portal turístico; b) a qualidade do produto e/ou serviço disponível para compra; c) o sistema de segurança e a privacidade da informação; e d) o serviço de pós-venda.

Desta forma, nota-se que o consumidor está preocupado, em primeiro lugar, com a segurança: ele quer acreditar que o portal turístico que está usando é confiável e contém informações autênticas. A qualidade das informações também é de extrema importância, pois é o que vai influenciar na hora da decisão da compra. A essência do produto e/ou serviço oferecido também é muito importante e, além disso, é necessário que os órgãos que desenvolvem e atualizam o site do destino ofereçam produtos de qualidade, cujo consumidor se sentirá satisfeito ao comprá-lo. Guimarães e Borges (2008) atentam para a importância qualitativa e quantitativa dos conteúdos de um website, responsáveis por "passarem confiança ao consumidor e se traduzirem em vantagem competitiva para a empresa ou destino".

Assim, entende-se que os órgãos públicos devem se preocupar com a qualidade das informações prestadas nos sites de destinos turísticos, pois essas informações formarão no turista uma imagem do destino e essa imagem pode ser tanto positiva quanto negativa, a depender da forma que as informações são divulgadas e da segurança e confiabilidade que o consumidor absorverá da fonte que está utilizando. 


\section{IMAGEM DO DESTINO TURÍSTICO}

Diferentemente de vários outros setores da economia, o turismo é uma atividade composta de múltiplos segmentos, e sua prática é formada por um conjunto de fatores que constroem uma experiência, algo intangível e que requer esforços de diferentes partes para que o sucesso seja obtido.

Uma vez que o turista vive de expectativas, ao visitar um destino ele estará utilizando de uma diversidade de serviços que precisam estar no mínimo em comum acordo com essas expectativas formadas inicialmente. Essa não é uma tarefa fácil, principalmente porque, ao final, se aquele turista tiver passado por problemas e situações indesejadas em sua viagem, o destino que ele estava visitando ficará marcado com uma imagem negativa.

Então, "como qualquer produto, as características da cidade são um instrumento para competir e diferenciar-se de outras cidades com as que pode entrar na competição para atrair seus clientes" (Elizangarate, 2003, p. 54).

Para gerar e atender a tais expectativas, os destinos turísticos estão desenvolvendo portais cada vez mais completos, tentando suprir as necessidades de seus usuários. Biz (2009) acredita que "as diretrizes de ordenamento, planejamento e promoção de um destino turístico passam pela identificação das necessidades e desejos dos consumidores, potenciais e reais". No caso dos websites de destinos turísticos, a eficiência seria vista como fornecer informações de qualidade para que todos os tipos de viajantes possam adquirir conhecimento a respeito do destino especificado e, a partir disso, tomar a decisão de consumir produtos e serviços oferecidos.

Dessa forma, os websites de destinos turísticos estão diretamente ligados à distribuição de informações para os consumidores que pretendem viajar para tal localidade, colaborando no planejamento de suas viagens e servindo como influência para a formação da opinião do turista sobre o lugar. Esses portais serão de fundamental importância para a formação da imagem do destino e possibilitarão que o consumidor tome a decisão de compra de vários serviços e produtos diferentes. 
Fica então evidente a necessidade de uma aliança entre as organizações públicas de turismo das cidades e as empresas que prestam serviços para o turismo da região, para que juntas, possam desenvolver estratégias que aprimore a formação dos sites de destinos, beneficiando assim tanto consumidores quanto o destino em si.

\section{PROCEDIMENTOS METODOLÓGICOS}

Os primeiros estudiosos que realizaram pesquisas dessa natureza já se utilizavam predominantemente de uma abordagem qualitativa, mas com limitação do número de pessoas que participavam do experimento, enquanto que a abordagem quantitativa foi incluída no decorrer dos anos (Law, Qi e Buhalis, 2010).

O presente estudo utiliza-se de uma abordagem qualitativa e caracterizase, quanto aos objetivos, como sendo de caráter descritivo-exploratório, já que busca explorar informações relacionadas ao tema com o objetivo de avaliar os principais sites de destinos turísticos em nível mundial, elencados no ranking de competitividade sociocultural da revista The Economist Inteligence Unit Limited (2012).

Cervo (2007) aponta que os estudos exploratórios têm por objetivo familiarizar-se com o fenômeno ou obter uma nova percepção dele e descobrir novas ideias. O autor também afirma que eles realizam descrições precisas da situação e buscam descobrir relações existentes entre seus elementos componentes, requerendo planejamento flexível para possibilitar a consideração dos mais diversos aspectos e de um problema ou de uma situação.

A interpretação dos fatos e a compreensão de significados são a base do processo de pesquisa qualitativa, que não exige técnicas estatísticas. A técnica utilizada é caracterizada pela pesquisa bibliográfica, feita com fontes secundárias, como livros e artigos científicos, por documentos fornecidos e pelas informações coletadas em websites. Uma das vantagens dessa técnica é que permite ao pesquisador um maior grau de amplitude (Dencker, 2007). 
A pesquisa também é considerada descritiva, pois mostra características condizentes a uma certa população ou fenômeno (Kahlmeyer-Mertens, 2007) que, no contexto deste trabalho, são portais que utilizam marketing digital para destinos turísticos.

A população da pesquisa envolveu os principais sites de destinos turísticos em nível mundial, presentes no ranking de competitividade sociocultural da revista The Economist Inteligence Unit Limited (2012), totalizando dez websites, A pesquisa buscou levantar dados por meio de uma ampla análise do tema, visando ao objetivo do trabalho em questão.

Desta forma, a pesquisa possui uma amostragem não probabilística. Uma listagem da população-alvo foi criada para aplicação do método Fatores Críticos do Sucesso. Com isso, fizeram parte da amostra os sites oficiais dos destinos que ficaram empatados nas três primeiras colocações (um total de dez) no ranking sociocultural da revista The Economist Inteligence Unit Limited (2012). Os websites são os seguintes: (1) www.zuerich.com; (2) www.discoverlosangeles. com; (3) www.nycgo.com; (4) www.sydney.com; (5) www.barce-lona-turisme. com; (6) www.visitberlin.de; (7) www.choosechicago.com; (8) www.frankfurttourismus.de; (9) www.visitlondon.com; (10) www.esmadrid.com/es/portal.do.

Quanto à natureza da pesquisa, a técnica utilizada para análise dos dados foi a análise de conteúdos e os dados foram coletados por dois meios: fontes primárias e secundárias.

Optou-se pelo uso de um instrumento de análise de websites turísticos que leva em consideração as variáveis definidas pelo estudo feito pela OMT (2005), que definiu um modelo de avaliação dos fatores críticos de sucesso, o "Evaluating and Improving Websites" (Avaliando e Melhorando Websites). Os procedimentos utilizados foram guiados por Ferreira et al. (2010), de forma a ser utilizado um "método de investigação heurística de usabilidade" sem a aplicação de questionário, a ser respondido pelo autor da pesquisa com base em coleta de dados na internet. Portanto, uma vez que a rede será a principal fonte de informações, ainda segundo o autor, "trata-se de um estudo descritivo, com pesquisa telematizada". 
O método de investigação utilizado foi o modelo de Fatores Críticos de Sucesso, proposto pela OMT (2005), mas que se baseia no conceito AIDA (Tomikawa, 2009), cujo conceito para websites foi o escolhido pelo IZT (Institute for futures Studies and Technology Assessment - Instituto para Estudos Futuros e Avaliação de Tecnologia) e DWIF (German Economic Institute For Tourism Research at Munich University - Instituto Econômico Alemão para Pesquisa e Turismo da Universidade de Munique).

O modelo AIDA trata da análise da influência do comportamento psicológico do usuário dos websites turísticos, buscando verificar se a visita a uma página na internet motivará o turista a viajar a um determinado destino. "O ponto de partida foi a crença de que a aparência e a estrutura da informação num site de turismo atrativo deveriam seguir o conceito AIDA, geralmente utilizado em marketing e envolvem Atenção, Interesse, Desejo e Ação", segundo Tomikawa (2009, p. 82).

Em seguida, serão enumeradas algumas sugestões da maneira como o marketing digital pode ser utilizado com melhor qualidade nos pontos fracos encontrados no estudo. Este tipo de análise é intitulado "Análise DAFO" (sigla para Deficiências, Ameaças, Fortalezas e Oportunidades), que provém do inglês "SWOT Analysis", que representa as iniciais das palavras Strengths (forças), Weaknesses (fraquezas), Opportunities (oportunidades) e Threats (ameaças). O termo "DAFO" é o utilizado no português e também pode ser definido como "FOFA": Forças, Oportunidades, Fraquezas e Ameaças (da Silva, Barreto e Ferreira, 2015). A análise "DAFO" será a segunda parte abordada, juntamente com a exposição da tabela comparativa entre os portais analisados e do ponto de vista dos autores, feita ao final do trabalho.

RESULTADOS

\section{FATORES CRÍTICOS DO SUCESSO}

Nesta área da pesquisa, foi elaborado um quadro comparativo contendo as variáveis dos Fatores Críticos de Sucesso proposto pela OMT (2005), as quais têm como base o conceito AIDA (Quadro 01) e todas as respostas compatíveis aos portais de cada destino (Quadro 02). 
Quadro 1 - Questionário comparativo AIDA.

\begin{tabular}{|c|c|c|}
\hline \multicolumn{3}{|c|}{ INSTRUMENTO PARA ANÁLISE DE WEBSITES TURÍSTICOS } \\
\hline VARIÁVEIS & DESCRIÇÃO & \begin{tabular}{|l} 
PERGUNTAS-CHAVE \\
\end{tabular} \\
\hline $\begin{array}{l}1^{\text {a) }} \text { ACCESSIBILITY } \\
\text { AND READABILITY } \\
\text { (ACESSIBILIDADE E } \\
\text { LEITURA) }\end{array}$ & $\begin{array}{l}\text { Acesso irrestrito a web por todos } \\
\text { independentemente da deficiência, } \\
\text { levando em conta limitações } \\
\text { visuais, de leitura, auditivas, físicas, } \\
\text { vocais, cognitivas e neurológicas } \\
\text { dos usuários potenciais, podendo } \\
\text { o sistema de informação ser } \\
\text { operado de várias maneiras (ex.: não } \\
\text { dependente de um navegador em } \\
\text { particular ou resolução do monitor, } \\
\text { além de poder ser visualizado em } \\
\text { outros aparelhos móveis como fones } \\
\text { e handheld). A acessibilidade está } \\
\text { ligada à encontrabilidade search } \\
\text { engine optimization, portanto deve } \\
\text { ser facilmente encontrada pelos } \\
\text { mecanismos de busca da web. }\end{array}$ & $\begin{array}{l}\text { A) Visual - o site possibilita leitura em braile? } \\
\text { B) Possui gráficos táteis ou de áudio? } \\
\text { C) Possui fonte pequena? } \\
\text { D) Físico - o site permite softwares de } \\
\text { reconhecimento de voz? } \\
\text { E) Possui formulários que podem ser } \\
\text { tabulados em ordem lógica? } \\
\text { F) Cognitivo e neurológico - o site utiliza } \\
\text { linguagem complexa? } \\
\text { G) Possui efeitos que fazem a página tremer? }\end{array}$ \\
\hline $\begin{array}{l}2^{\mathrm{a}} \text { ) IDENTITY AND } \\
\text { TRUST (IDENTIDADE E } \\
\text { CONFIANÇA) }\end{array}$ & $\begin{array}{l}\text { O site deve assegurar que o } \\
\text { conteúdo e o design inspirem } \\
\text { confiança no usuário. }\end{array}$ & $\begin{array}{l}\text { A) A URL do site tem relação com o } \\
\quad \text { nome do destino? } \\
\text { B) Deixa claro que é o site oficial de } \\
\quad \text { turismo do destino? } \\
\text { C) Utiliza imagens reais do destino? } \\
\text { D) Indica as fontes das informações } \\
\quad \text { presentes no site? }\end{array}$ \\
\hline \multicolumn{3}{|c|}{ INSTRUMENTO PARA ANÁLISE DE WEBSITES TURÍSTICOS - continuação } \\
\hline VARIÁVEIS & DESCRIÇÃO & PERGUNTAS-CHAVE \\
\hline $\begin{array}{l}3^{\mathrm{a})} \text { CUSTOMIZATION } \\
\text { AND INTERACTIVITY } \\
\text { (CUSTOMIZAÇÃO E } \\
\text { INTERATIVIDADE) }\end{array}$ & $\begin{array}{l}\text { Forneça possibilidade de contato. } \\
\text { Questões ligadas ao controle direto } \\
\text { do usuário, em que ele possa } \\
\text { explicitamente selecionar entre certas } \\
\text { opções. }\end{array}$ & $\begin{array}{l}\text { A) O site fornece possibilidade de contato? } \\
\text { B) Fornece mecanismo interno de busca? } \\
\text { C) Possui mapa de localização do } \\
\text { próprio site? } \\
\text { D) Fornece ajuda nos principais serviços? } \\
\text { E) Fornece navegação diferenciada por } \\
\text { perfil (turistas, organizadores de eventos, } \\
\text { imprensa, parceiros de negócios)? } \\
\text { F) Oferece navegação diferenciada por } \\
\text { atividade procurada (hotel, eventos, } \\
\text { atrativos turísticos, entre outros)? } \\
\text { G) Fornece ferramenta de } \\
\text { planejamento de roteiro? } \\
\text { H) Possui disponibilidade em vários idiomas? }\end{array}$ \\
\hline $\begin{array}{l}\left.4^{\mathrm{a}}\right) \text { NAVIGATION } \\
\text { (NAVEGAÇÃO) }\end{array}$ & $\begin{array}{l}\text { A navegação é a representação da } \\
\text { arquitetura da informação (a estrutura) } \\
\text { do website e o mecanismo pelo qual } \\
\text { os usuários se movem pelo mesmo. } \\
\text { Os princípios básicos de como } \\
\text { encorajar os usuários a navegar pelo } \\
\text { conteúdo do website estão entre os } \\
\text { mais importantes fatores críticos que } \\
\text { determinam a usabilidade do mesmo. } \\
\text { Grande parte da interação entre } \\
\text { usuário e interface é determinada por } \\
\text { meio dos itens de navegação. }\end{array}$ & $\begin{array}{l}\text { A) O site responde em todas as páginas: } \\
\text { Em que site estou? } \\
\text { B) Onde estou dentro do site? } \\
\text { C) O que posso fazer aqui? } \\
\text { D) Para onde posso ir daqui? } \\
\text { E) Onde está a informação que } \\
\text { estou buscando? } \\
\text { F) O site possui links que interligam } \\
\text { páginas relacionadas? }\end{array}$ \\
\hline
\end{tabular}




\section{5) FINDABILITY AND SEARCH ENGINE OPTIMIZATION (ENCONTRABILIDADE E OTIMIZAÇÃO DOS MECANISMOS DE BUSCA)}

\section{6 ${ }^{\text {a) }}$ TECHNICAL PERFORMANCE (DESEMPENHO TÉCNICO)}

O website deve aparecer na primeira página de busca dos principais mecanismos de busca, como Google, Yahoo e MSN.

\section{Todos os elementos do website} devem ser compatíveis com os browsers mais comuns, como Internet Explorer, Mozilla Firefox, Google Chrome, entre outros. As páginas devem carregar rapidamente com as respectivas imagens e logomarcas; os links internos e externos devem estar funcionando; o site deve indicar claramente se algum software ou plug-in adicional é necessário e os links para os sites onde eles possam ser baixados devem ser fornecidos;

as páginas devem ser impressas corretamente ou uma versão para impressão é oferecida.
A) O site aparece na primeira página do Google, Yahoo e/ou MSN?

A) O site possui os elementos compatíveis com a Internet Explorer,

Mozilla e/ou Google Chrome?

B) As paginas estâo carregando rapidamente?

C) Os links estão funcionando? D) O site indica se é preciso instalar algum software ou plug-in adicional e indica os sites onde estes podem ser baixados?

E) As páginas são impressas corretamente e/ou indicam para uma versão de impressão?

INSTRUMENTO PARA ANÁLISE DE WEBSITES TURÍSTICOS - continuação

VARIÁVEIS DESCRIÇÃO

A qualidade de um website pode ser medida em termos da qualidade dos serviços que ele oferece. Os tipos de serviços disponíveis na web são: serviços de informação; serviços de contato; serviços de transação; serviços de entretenimento; serviços de relacionamento.
PERGUNTAS-CHAVE

A) O website oferece serviços diversificados?

Fonte: Autoria própria.

Quadro 2 - Quadro comparativo dos websites pesquisados.

\begin{tabular}{|c|c|c|c|c|c|c|c|c|c|c|}
\hline \multirow{2}{*}{ AIDA } & \multicolumn{10}{|c|}{ PORTAIS TURÍSTICOS - WEBSITES DAS CIDADES } \\
\hline & ZURICH & L.A. & N.Y. & SYDNEY & BARCELONA & BERLIN & CHICAGO & FRANKFURT & LONDRES & MADRID \\
\hline 1.a & Não & Não & Não & Não & Não & Não & Não & Não & Sim & Sim \\
\hline 1.b & Sim & Não & Não & Não & Não & Não & Não & Não & Não & Não \\
\hline 1.C & Satisf. & Satisf. & Satisf. & Satisf. & Satisfatório & Satisf. & Satisf. & Satisf. & Satisf. & Satisf. \\
\hline 1.d & Não & Não & Não & Não & Não & Não & Não & Não & Não & Não \\
\hline 1.e & Sim & Sim & Sim & Sim & Sim & Sim & Sim & Sim & Sim & Sim \\
\hline $1 . f$ & Não & Não & Não & Não & Não & Não & Não & Não & Não & Não \\
\hline 1.9 & Não & Não & Não & Não & Não & Não & Não & Não & Não & Não \\
\hline 1.h & Sim & Sim & Sim & Sim & Sim & Sim & Sim & Sim & Sim & Sim \\
\hline 2.a & Sim & Sim & Sim & Sim & Sim & Sim & Sim & Sim & Sim & Sim \\
\hline 2.b & Sim & Não & Sim & Sim & Não & Sim & Sim & Não & Sim & Não \\
\hline 2.c & Sim & Sim & Sim & Sim & Sim & Sim & Sim & Sim & Sim & Sim \\
\hline 2.d & Não & Não & Não & Não & Não & Event. & Não & Não & Sim & Event. \\
\hline 3.a & Sim & Sim & Sim & Sim & Sim & Sim & Sim & Sim & Sim & Sim \\
\hline 3.b & Sim & Sim & Sim & Sim & Sim & Sim & Sim & Sim & Sim & Sim \\
\hline 3.c & Sim & Não & Não & Sim & Sim & Sim & Sim & Sim & Sim & Sim \\
\hline 3.d & Sim & Sim & Sim & Sim & Sim & Sim & Sim & Sim & Sim & Sim \\
\hline 3.e & Sim & Sim & Sim & Sim & Sim & Sim & Sim & Não & Sim & Sim \\
\hline 3.f & Sim & Sim & Sim & Sim & Sim & Sim & Sim & Sim & Sim & Sim \\
\hline 3.9 & Sim & Sim & Sim & Sim & Sim & Sim & Sim & Sim & Sim & Sim \\
\hline 3.h & Sim & Não & Sim & Sim & Sim & Sim & Sim & Sim & Sim & Sim \\
\hline 4.a & Sim & Sim & Sim & Sim & Sim & Sim & Sim & Sim & Sim & Sim \\
\hline 4.b & Sim & Sim & Sim & Sim & Sim & Sim & Sim & Sim & Sim & Sim \\
\hline
\end{tabular}


DoI: 10.14210/rtva.v18n2.p557-583

\begin{tabular}{|c|c|c|c|c|c|c|c|c|c|c|}
\hline $4 . c$ & Sim & Sim & Sim & Sim & Sim & Sim & Sim & Sim & Sim & Sim \\
\hline 4.d & Sim & Sim & Sim & Sim & Sim & Sim & Sim & Sim & Sim & Sim \\
\hline 4.e & Sim & Sim & Sim & Sim & Sim & Sim & Sim & Sim & Sim & Sim \\
\hline 4.f & Sim & Sim & Sim & Sim & Sim & Sim & Sim & Sim & Sim & Sim \\
\hline 5 & Sim & Sim & Sim & Sim & Sim & Sim & Sim & Sim & Sim & Sim \\
\hline 6.a & Sim & Sim & Sim & Sim & Sim & Sim & Sim & Sim & Sim & Sim \\
\hline $6 . b$ & Sim & Sim & Sim & Sim & Sim & Sim & Sim & Sim & Sim & Sim \\
\hline $6 . c$ & Sim & Sim & Sim & Sim & Sim & Sim & Sim & Sim & Sim & Sim \\
\hline $6 . d$ & Não & Não & Não & Não & Não & Não & Não & Sim & Não & Não \\
\hline $6 . e$ & Sim & Sim & Sim & Sim & Sim & Sim & Sim & Sim & Sim & Sim \\
\hline 7 & Sim & Sim & Sim & Sim & Sim & Sim & Sim & Sim & Sim & Sim \\
\hline
\end{tabular}

Fonte: Dados da pesquisa (2012).

\section{QUADRO DE ANÁLISE “DAFO”}

A partir da análise feita nos dez websites oficiais de turismo das cidades que ficaram empatados entre as três primeiras posições no ranking promovido pela revista The Economist Inteligence Unit Limited no quesitos social e cultural, percebeu-se que existem pontos positivos e negativos em todos eles. Desta maneira, este tópico irá listar algumas das fortalezas e algumas das fraquezas encontradas, visando contribuir para melhoria e evolução dos portais.

A análise "DAFO" é utilizada na gestão e no planejamento estratégico e visa analisar o cenário em questão. É composta pela avaliação do ambiente interno, do qual fazem parte as deficiências e as fortalezas; e do ambiente externo, que engloba as ameaças e as oportunidades. A seguir, a Tabela 03 apresenta a análise "DAFO" dos portais turísticos analisados por esta pesquisa:

Quadro 3 - Análise "DAFO" dos websites pesquisados.

\begin{tabular}{|c|c|}
\hline \multicolumn{2}{|c|}{ ANÁLISE “DAFO” DOS WEBSITES PESQUISADOS } \\
\hline \multicolumn{2}{|c|}{ FATORES INTERNOS } \\
\hline DEFICIÊNCIAS & $\begin{array}{l}\text { FORTALEZAS } \\
\end{array}$ \\
\hline $\begin{array}{l}\text { 1. A questão da acessibilidade em websites ainda não } \\
\text { é muito bem explorada, e a maioria dos portais não } \\
\text { apresentou ferramentas que facilitassem o seu acesso } \\
\text { por portadores de deficiências. }\end{array}$ & $\begin{array}{c}\text { 1. A organização dos portais quanto aos itens, } \\
\text { divididos em tópicos por assuntos, numa ordem } \\
\text { lógica, facilita a compreensão destes por parte } \\
\text { do usuário que consegue se localizar em meio a } \\
\text { tanta informação. }\end{array}$ \\
\hline $\begin{array}{l}\text { 2. Os layouts de alguns portais não são atrativos, o } \\
\text { que limita sua interação com o consumidor on-line, } \\
\text { influenciando na opinião em relação à eficiência } \\
\text { do portal. É necessário criar um ambiente em que } \\
\text { o usuário se sinta confortável e, ao mesmo tempo, } \\
\text { atraído pelas imagens e informações prestadas, para } \\
\text { que adquira os serviços e produtos oferecidos. }\end{array}$ & $\begin{array}{l}\text { 2. Oferecer navegação diferenciada por perfil } \\
\text { de visitante e por atividade procurada contribui } \\
\text { para que todos os usuários tenham acesso às } \\
\text { informações que buscam e consigam encontrar } \\
\text { os dados que precisam. }\end{array}$ \\
\hline
\end{tabular}




\section{Alguns portais não deixam claro para o consumidor} de que se trata do website oficial de turismo do destino. Esse fator prejudica a confiabilidade que o usuário terá com o portal, podendo fazer com que o leitor não se sinta seguro em adquirir os serviços prestados e não confie nas informações disponibilizadas, buscando outras fontes de pesquisa para elaborar seu roteiro de viagens.

4. Alguns portais ainda não oferecem seus serviços em mais de um idioma. Essa é uma deficiência que fará com que os usuários que não tenham conhecimento da língua oficial do país em questão tenham grandes dificuldades ao navegar o site. Alguns portais, apesar de oferecerem mais de um idioma, possuem algumas páginas que não são traduzidas. Esse problema ocorre com frequência e pode prejudicar a relação entre o consumidor e a busca por informações.
3. As ferramentas de compras, que por um lado não são bem exploradas por certos websites, são um fator positivo em outros. Alguns portais possibilitam que o consumidor compre (serviços, ingressos, reservas, dentre outros) diretamente na página do portal. Essa ferramenta é muito útil e aumenta a satisfação do cliente pelo serviço prestado.

4. Hoje, a globalização contribui para que o contato entre os portais e o usuário seja maior e mais fácil. Todos os websites pesquisados possuem páginas em redes sociais, facilitando a comunicação destes com o consumidor e deixando o usuário por dentro das novidades existentes.

\section{ANÁLISE "DAFO" DOS WEBSITES PESQUISADOS - continuação FATORES INTERNOS}

\begin{tabular}{|c|}
\hline DEFICIÊNCIAS \\
\hline 5. Muitos dos portais ainda não aparecem na primeira \\
página ao serem pesquisados em português nos \\
mecanismos de busca como Google, Yahoo e MSN. \\
Países de língua portuguesa, principalmente o Brasil, \\
estão se desenvolvendo e se tornando grandes \\
emissores de turistas. É importante que os turistas \\
brasileiros em potencial tenham acesso a esses \\
portais, mesmo se não buscarem por eles em inglês.
\end{tabular}

6. Problemas de funcionalidade foram encontrados em links de alguns dos portais pesquisados. Em sua maioria, os problemas não ocorriam nos itens de maior importância, porém os portais devem estar preparados para que todos os links e ferramentas fornecidos estejam funcionando.

7. Ferramentas de compra (desde serviços à ingressos de atrações) podem ser melhoradas. Muitos dos dados sobre atrações locais não oferecem a compra dos ingressos no próprio website, dificultando o acesso do consumidor àqueles.

\section{FORTALEZAS}

5. Os portais são uma importante fonte de informações para os turistas e o fato de eles estarem disponíveis na internet, oferecendo seus serviços gratuitamente, é muito positivo. São os legados da tecnologia permitindo que pessoas e empresas em todo o mundo consigam se comunicar de maneira rápida, fácil e eficiente.

6. Um dos principais pontos positivos dos portais turísticos on-line é o fato de esses possibilitarem que turistas dos mais variados países tenham acesso às informações sobre

o destino que pretendem visitar. Os sites pesquisados fornecem dados que permitem que o consumidor elabore um roteiro turístico e planeje sua viagem de forma satisfatória. Mesmo os portais que se mostraram menos completos contribuem para que o leitor adquira informações importantes sobre a cidade em questão e possa decidir o que deseja visitar.

7. Os custos da utilização do marketing on-line podem ser menores, permitindo que os portais usem essa estratégia para atrair turistas para o destino em questão mais facilmente.

FATORES EXTERNOS

\section{AMEAÇAS}

1. Muitos são os websites que representam um destino turístico na internet. Quando se pesquisa por uma cidade em específico, vários endereços aparecem e fica difícil decidir qual o melhor website para se utilizar. A concorrência é muito grande e os portais oficiais dos destinos precisam se esforçar

para que os consumidores tenham acesso às informações de qualidade.

\section{OPORTUNIDADES}

1. O crescente uso da internet pela população mundial possibilita que mais e mais pessoas tenham acesso aos portais turísticos e se beneficiem das informações presentes neles. Isso possibilita que o número de usuários cresça e os portais se desenvolvam ainda mais.

2. O surgimento de novas tecnologias permite que os portais de turismo evoluam e criem novas ferramentas para facilitar seu acesso pelos consumidores. 
2. Confiabilidade é um quesito importante que as portais de destinos turísticos precisam alcançar. É fundamental que as informações prestadas sejam autênticas, pois muitas são as chances do usuário não se sentir seguro ao navegar o portal. Por isso é preciso cada vez mais, investir na segurança das informações, proporcionando aos leitores dados de qualidade.
3. Parcerias com a iniciativa privada podem contribuir para que os websites de destinos turísticos fiquem mais completos. É importante oferecer aos consumidores o maior número de serviços e produtos para que optem por aquilo que melhor se encaixa em suas necessidades.

4. Estratégias de marketing podem ser desenvolvidas para que os portais turísticos influenciem cada vez mais nas decisões dos consumidores. A internet tem um grande alcance e pode distribuir informações importantes para um grande número de pessoas ao redor do mundo.

ANÁLISE “DAFO” DOS WEBSITES PESQUISADOS - continuação

FATORES EXTERNOS

\begin{tabular}{|c|c|}
\hline AMEAÇAS & OPORTUNIDADES
\end{tabular}

3. A partir dos portais oficiais de turismo, o consumidor vai criar uma expectativa em relação ao destino pesquisado. Irá formar uma imagem da cidade ao navegar o website, ao ler as informações que este disponibiliza. Deste modo, é crucial que os dados oferecidos sejam reais, já que ao planejar um roteiro usando suas informações o turista estará acreditando neles. Se as informações forem ineficientes ou errôneas, o turista irá se decepcionar ao chegar ao destino e criará uma imagem negativa tanto do portal quanto da cidade. Além de que o simples fato de conter informações de baixa qualidade pode influenciar diretamente na opção do consumidor de não visitar aquele lugar.

5. Parcerias com a comunidade acadêmica podem ser realizadas para que pesquisas contribuam para um melhor planejamento estratégico dos websites de destinos turísticos.

Fonte: Autoria própria.

\section{CONSIDERAÇÕES FINAIS}

O crescimento do uso da internet pelos consumidores do setor do turismo vem ocasionando a criação de novas estratégias para a elaboração e planejamento de portais turísticos on-line, visando a uma maior interação entre empresas e destinos com o cliente. A importância desses websites para o turista é percebida devido às mudanças do mercado do turismo. Grande parte dos serviços e produtos turísticos são comprados pela internet, o que evidencia a influência que esta tem sobre o comprador.

Os websites de destinos turísticos, por sua vez, são fundamentais para que turistas de várias partes do mundo tenham acesso às informações que precisam para visitarem uma determinada localidade. Acessando esses portais o consumidor irá ter a chance de se comunicar com estabelecimentos locais e planejar seu roteiro de viagens independentemente. 
Desta forma, o presente trabalho buscou analisar as condições em que os portais de destinos turísticos se encontram, verificando se as informações distribuídas por aqueles são de qualidade e verificar se estas possibilitam que o turista planeje sua viagem de maneira satisfatória.

A partir da análise feita, percebeu-se que a maioria dos portais selecionados para a pesquisa são capazes de colaborar na elaboração de um bom roteiro de viagens, além de permitirem também que o consumidor planeje sua viagem de maneira independente, podendo pesquisar sua acomodação e restaurantes desejados.

Os portais também possibilitam que o consumidor tenha uma ideia de como funciona o destino em questão, apresentando mapas, imagens e informações em geral que deixam o usuário bem informado, deixando que este se sinta mais seguro em fazer a viagem.

Entretanto, mesmo sendo capazes de informar o consumidor e colaborar para que este planeje sua viagem pela internet, sem precisar da ajuda de intermediários (agências de viagens e operadoras turísticas), os portais apresentaram algumas fragilidades que devem ser solucionadas para melhorar seu acesso. Mesmo sendo websites de grandes destinos turísticos internacionais, alguns não demonstraram muita atratividade em seus layouts, como foi o caso do portal de Barcelona, Frankfurt e Madrid.

A questão da acessibilidade foi outro ponto negativo encontrado na maioria dos portais pesquisados. Apenas os websites de Zurich, Londres e Madrid se preocuparam em fornecer ferramentas de acesso que facilitassem o seu uso por portadores de deficiências. Esse dado é muito importante, pois mostra que a acessibilidade na internet também deve ser incentivada, e os órgãos de turismo devem se preocupar com este assunto e criar estratégias para solucionar o problema.

As informações, em geral fornecidas pelos portais, podem ser mais completas. Muitas não permitem que o usuário tenha um total entendimento do assunto. Isso ocorre principalmente em relação aos tópicos relacionados às atrações locais menos populares. Geralmente, não são informados detalhes importantes, como informações sobre compra de ingressos, horários, como chegar, dentre 
outras informações que são importantes para o turista de primeira viagem. Contudo, quando se trata das atrações principais do destino em questão, os portais disponibilizam informações mais detalhadas.

A questão do idioma também foi outro ponto analisado. Alguns portais não oferecem mais de um idioma aos seus usuários. Em muitos, apenas o inglês está presente, o que se mostra um grande impasse para que esses sites atendam à demanda de turistas estrangeiros que não são fluentes no inglês. É bastante recomendável que os órgãos e as entidades de turismo local invistam na tradução dos conteúdos dos portais para vários idiomas, permitindo que turistas de um número maior de nacionalidades tenham acesso às informações.

Deste modo, o presente trabalho percebeu que os websites de destinos turísticos em geral, mesmo aqueles dos principais destinos mundiais, carecem de informações e ferramentas importantes. É preciso que os órgãos de turismo local fiquem cada vez mais atentos às necessidades de seus consumidores (turistas em potencial ou não) para que desenvolvam portais mais eficientes e que atendam de maneira satisfatória aos desejos de seus clientes. É recomendado também que o foco seja primeiramente em elementos básicos, que transmitam credibilidade e partir para a utilização de ferramentas como webcams, mural de recados, dentre outros, com a intenção de fazer o site receber um maior número de visitantes (Loda et al., 2009).

É proposto, portanto, que exista um monitoramento constante nos sites turísticos das cidades, para mantê-los sempre atualizados e por dentro das novidades e dos eventos que estão ocorrendo na localidade em questão. Devem ser realizadas frequentes pesquisas de mercado, visando descobrir as mudanças do comportamento dos consumidores e turistas da região e do mundo, para melhor atender seu público. Um banco de dados dos usuários que acessam os sites seria uma maneira eficiente de estar conectado com os compradores e seria, também, uma maneira de entender seus desejos e, desta forma, conseguir atendê-los. 
BALOGLU, S., \& MANGALOGLU, M. (2001). Tourism destination images of Turkey, Egypt, Greece, and Italy as perceived by US-based tour operators and travel agents. Tourism management, 22(1), 1-9.

BIZ, A. (2009). Avaliação dos portais turísticos governamentais quanto ao suporte à gestão do conhecimento. 231 f. Tese (Doutorado) - Programa de Pós-Graduação em Engenharia do Conhecimento, Universidade Federal de Santa Catarina, Florianópolis.

BIZ, A., CERETTA, F. (2008). Modelo de gerenciamento do fluxo de informação dos portais turísticos governamentais uma abordagem teórica. Turismo-Visão e Ação, 10(3), 399-414.

BRILHANTE, M., CORRÊA, C. (2015). Análise comparativa de guias turísticos em formato de aplicativo: Lonely Planet e MTRIP. Turismo-Visão e Ação, 17(2), 354-386.

BUHALIS, D. (1998). Strategic use of information technologies in the tourism industry. Tourism management, 19(5), 409-421.

CERVO, L.; BERVIAN, P.; SILVA, R. (2007) Metodologia Científica. 6. ed. São Paulo: Pearson Prentice Hall.

CHOI, S., LEHTO, X., \& MORRISON, A. (2007). Destination image representation on the web: Content analysis of Macau travel related websites. Tourism Management, 28(1), 118-129.

COOPER, C., FLETCHER, J., FYALL, A., GILBERT, D., WANHILL, S. (2007). Turismo: princípios e práticas. Bookman.

CORPAS, Elena; GARCIA, Laura. El producto Barcelona dentro y fuera de la ciudad. Métodos y técnicas de investigación II. Barcelona, 2007.

DA SILVA, I., BARRETO, L., \& FERREIRA, L. (2015). Turismo de bem-estar: análise dos serviços do segmento em spas day-Natal/RN, Brasil. RITUR-Revista Iberoamericana de Turismo, 5(2), 99-118.

DEDEKE, A. (2016). Travel web-site design: Information task-fit, service quality and purchase intention. Tourism Management, 54, 541-554.

DENCKER, A. (2007). Pesquisa em turismo: planejamento, métodos e técnicas. Futura.

ELIZANGARATE, Victoria (2003). Marketing de ciudades. Madrid: Pirámide. 
GUIMARÃES, S., BORGES, P. (2008) E-turismo: internet e negócios do turismo. São Paulo: Cengage Learning.

HYDE, K. (2006). Contemporary information search strategies of destination-naïve international vacationers. Journal of Travel \& Tourism Marketing, 21(2-3), 63-76.

IBGE. Acesso à internet e posse de telefone móvel celular para uso pessoal 2011. Disponível em: <http://www.ibge.gov.br> Acesso em: 12 abr. 2016.

ITU. Key statistical highlights: ITU data release 2015. Disponível em: < http://www.itu.int/ ITU-D/ict/index.html>. Acesso em: 12 abr. 2016.

KAHLMEYER-MERTENS, Roberto S. et. al. Como elaborar projetos de pesquisa. Rio de Janeiro: Editora FGV, 2007.

KOTLER, P., KARTAJAYA, H., \& SETIAWAN, I. (2010). Marketing 3.0: as forças que estão definindo o novo marketing centrado no ser humano. Elsevier.

KUO, P., ZHANG, L., \& CRANAGE, D. (2015). What you get is not what you saw: exploring the impacts of misleading hotel website photos. International Journal of Contemporary Hospitality Management, 27(6), 1301-1319.

LAW, R., QI, S., \& BUHALIS, D. (2010). Progress in tourism management: A review of website evaluation in tourism research. Tourism management, 31(3), 297-313.

LODA, M., D., TEICHMANN, K.,ZINS,A.(2009).Destinationwebsites' persuasiveness.International journal of culture, tourism and hospitality research, 3(1), 70-80.

LOHMANN, G., \& PANOSSO NETTO, A. (2012). Teoria do turismo: conceitos, modelos e sistemas. São Paulo: Aleph.

MENDES FILHO, L. (2014). Empowerment in the context of user-generated content in the travel industry: a research model proposal. El Periplo Sustentable, (27).

MINISTÉRIO DO TURISMO (2009). Hábitos de consumo do turista brasileiro. Brasília, 2009. Disponível em: <http://www.turismo.gov.br> Acesso em: 12 abr. 2016

MORRISON, A. M. (2012). Marketing de hospitalidade e turismo. Cengage Learning, São Paulo.

OMT - Organização Mundial do Turismo (Org.). Tourism-Basic Glossary. Disponível em: < http:// www.unwto.org/pdf/Understanding_Tourism-BasicGlossary_EN.pdf>. Acesso em: 12 abr 2016.

RODRÍGUEZ-MOLINA，M., FRÍAS-JAMILENA， D., \& CASTAÑEDA-GARCÍA，J. (2015). The contribution of website design to the generation of tourist destination image: The moderating effect of involvement. Tourism Management, 47, 303-317. 
RUSCHMANN, D., TOMELIN, C. (2013). Turismo, ensino e práticas interdisciplinares. Barueri: Manole.

TOMIKAWA, J. (2009) Marketing Turístico e Internet: uma análise dos sites oficiais de turismo dos estados Brasileiros. 2009, 160f. Dissertação (Mestrado em Turismo) - Centro de Excelência em Turismo da Universidade de Brasília, DF. 